\title{
sala

\section{A SALA DE AULA INVERTIDA COMO ALTERNATIVA INOVADORA PARA A EDUCAÇÃO BÁSICA}

\section{THE FLIPPED CLASSROOM AS AN INNOVATIVE ALTERNATIVE FOR PRIMARY EDUCATION}

\author{
LUIZ GUSTAVO DA SILVA BISPO ANDRADE ${ }^{1}$ \\ Instituto Federal de Educação, Ciência e Tecnologia de Sergipe \\ E-mail: luiz.gustavosb2016@gmail.com \\ LUCAS ANTÔNIO FEITOSA DE JESUS² \\ Instituto Federal de Educação, Ciência e Tecnologia de Sergipe \\ E-mail: I.a.f.j@hotmail.com \\ RODRIGO BOZI FERRETE ${ }^{3}$ \\ Instituto Federal de Educação, Ciência e Tecnologia de Sergipe \\ E-mail: rbferrete@gmail.com \\ RONNEY MARCOS SANTOS ${ }^{4}$ \\ Universidade Federal de Sergipe \\ E-mail: ronneymarcos@gmail.com
}

\begin{abstract}
Resumo: Este artigo trata das metodologias ativas de aprendizagem, especificamente a sala de aula invertida e o que ela pode significar no processo de ensino-aprendizagem. Essa abordagem é conhecida como Flipped Classroom, na qual o aluno tem contato com o conteúdo escolar antes de estar na sala de aula, fazendo uso da internet como recurso de aprendizado. Pautou-se numa pesquisa bibliográfica, seguido de um estudo de caso sobre o uso da metodologia em sala de aula, na qual fizemos a articulação das ideias de respeitados autores que tratam de metodologias ativas e inversão da sala de aula. $O$ trabalho foi desenvolvido em uma escola pública da Rede Estadual de Sergipe, em cinco turmas de Língua Portuguesa da terceira série do Ensino Médio. Através do trabalho desenvolvido, percebemos o interesse dos alunos, quando elogiavam o fato de já irem à aula sabendo o que seria discutido, o que nos fazia ganhar tempo para as discussões, como também para amadurecê-las, elevando o rendimento dos estudantes. Desde 2017, que as notas de redação das turmas, em avaliações internas e externas, cresceram exponencialmente, comprovando mais uma vez a eficácia do método.
\end{abstract}

Palavras-chave: Educação Básica. Metodologia ativa. Sala de aula invertida. Tecnologias Digitais.

\footnotetext{
${ }^{1}$ Mestrando em Educação Profissional e Tecnológica do Instituto Federal de Educação, Ciência e Tecnologia de Sergipe; Especialista em Docência do Ensino Superior (FASE); Especialista em Coordenação Pedagógica (UFS); graduado em Pedagogia (FAMA). Atualmente é Professor de Educação Básica - SEDUC-SE. E-mail: luiz.gustavosb2016@gmail.com

${ }^{2}$ Mestrando em Educação Profissional e Tecnológica do Instituto Federal de Educação, Ciência e Tecnologia de Sergipe; Graduado em Licenciatura plena em Ciências Biológicas pela Universidade Federal de Sergipe e especialista em Filosofia pela Faculdade Internacional Signorelli.

${ }^{3}$ Professor efetivo do Instituto Federal de Sergipe (IFS), lotado na Coordenação do Curso de Licenciatura em Matemática. Professor do Mestrado em Educação Profissional e Tecnológica do IFS. Doutor em Educação pela Universidade Federal de Sergipe, Mestre em Educação pela Universidade Federal do Rio Grande do Norte e graduado em Licenciatura em Matemática pela Universidade do Estado do Pará.

${ }^{4}$ Doutorando em Estudos Linguísticos pela Universidade Federal de Sergipe (PPGL/UFS). Possui Graduação (2011) e Mestrado (2014) em Letras pela Universidade Federal de Sergipe. Pesquisador do Grupo de Pesquisa Linguagem, Enunciação e Discurso para o Ensino de Língua Portuguesa (LED/UFS).
} 


\section{sala \\ de \\ aula foco}

-REVISTA ELETRÔNICA

Abstract: This article focuses on active learning methodologies, specifically the Flipped Classroom, and what it can mean in the teaching-learning process. This approach is known as the Flipped Classroom, in which the student has contact with the school content before being in the classroom, making use of the Internet as a learning resource. Bibliographical research guided this study, which was followed by a case study on the use of the methodology in the classroom, in which we articulated the ideas respected authors dealing with active learning methodologies and Flipped Classroom. The case study took place in a public school in the State of Sergipe, in five Portuguese language classes of the third grade of high school. Through the work developed, we noticed the interest of the students, when they praised the fact that they already went to class knowing about what would be discussed, which saved us time for the discussions, as well as to mature them, increasing the students' performance. Since 2017, the class scores in internal and external assessments have grown exponentially, once again proving the effectiveness of the method.

Keywords: Primary education. Active methodology. Flipped Classroom. Digital Technologies.

\section{INTRODUÇÃO}

$\mathrm{Na}$ sociedade atual, as pessoas têm se tornado cada vez mais adeptas às tecnologias. A escola não está alheia a esses avanços, principalmente por conta da geração que a compõe, cercada por novidades tecnológicas. Devido à essas transformações, as concepções de ensino têm sido questionadas, havendo necessidade de novas técnicas que vão de encontro ao modelo tradicional escolar, pautado na exposição de conteúdo e na maneira como o tempo de aula é planejado.

Assim, faz-se necessário agir de maneira diferente da sala de aula convencional, a qual estamos acostumados, a partir de conceitos inovadores, objetivando tornar o discente um agente ativo de sua aprendizagem, tendo que para isso, formar o professor na adoção de métodos que promovam essa autonomia.

$\mathrm{Na}$ abordagem tradicional de ensino é o professor quem controla a maneira como os conteúdos são apresentados aos alunos. Contrariando essa ideia, hoje existem inúmeras possibilidades que emergem das Metodologias Ativas, para favorecer a ação educativa discente: estudo de caso, a instrução pelos pares (do inglês peer instruction), o método de projetos, a aprendizagem baseada em problemas (também conhecida pela sigla PBL, iniciais do termo em inglês Problem Based Learning), a sala de aula invertida (do inglês Flipped Classroom), entre outras. 


\section{sala \\ de $\oplus$ em \\ aula 1 foco}

Esse artigo trata especificamente sobre o uso da sala de aula invertida, que de acordo com Moran (2018) é a ampliação da sala de aula, transformando outros espaços físicos, inclusive espaços virtuais, tornando possível que o "mundo" seja também um lugar de aprendizado. Parece algo simples, todavia exige uma reconfiguração da sala de aula e uma mudança de cultura para esse ambiente.

A Sala de Aula Invertida (SAI) é uma técnica de ensino mediada pelas Tecnologias Digitais da Informação e Comunicação (TDIC), e como o próprio nome deixa evidente, ela inverte a lógica tradicional de ensino, na qual o aluno comparece à escola para receber o conteúdo através da exposição docente. Nessa proposta, o aluno tem contato antecipado com os assuntos que irá aprender através de atividades em casa por meio do ensino on-line. E o que fazer com o tempo que sobra em sala de aula? Em sala, os alunos são incentivados a trabalhar em equipes, de forma colaborativa, tendo o professor como mediador entre si e realização de suas atividades.

Com a antecipação do conteúdo (premissa da Sala de Aula Invertida), cria-se também a possibilidade de otimização do tempo em sala de aula. O tempo que seria gasto com a transmissão de informações passa a ser de engajamento entre professor e aluno, o que se torna uma vantagem para ambos, o que ocorreu na intervenção pedagógica realizada.

Diante dos benefícios descritos, pelas referências que enaltecem essa metodologia ativa de aprendizagem até aqui, que professor não buscaria fazer uso dela para comprovar tal eficácia? Foi com base nas leituras realizadas e na curiosidade de pesquisadores que nos propomos a colocá-la em prática de forma experimental.

\section{METODOLOGIA}

De pesquisa bibliográfica e experimental, o artigo em questão faz parte do programa de atividades do Mestrado Profissional em Educação Profissional e Tecnológica (ProfEPT), do Instituto Federal de Educação, Ciência e Tecnologia de Sergipe (IFS), em consonância com a prática de sala de aula através da parceria com um professor da Rede Estadual de Ensino do Estado de Sergipe, a 


\section{sala \\ de $\oplus$ em \\ aula foco}

partir da experimentação em sua prática docente no Centro de Excelência Atheneu Sergipense, escola de ensino médio da cidade de Aracaju.

Apoiados em pesquisadores que trabalham com a temática, fizemos uma busca a partir do Google Acadêmico (scholar.google.com.br), do Banco de Teses e Dissertações da Capes (bancodeteses.capes.gov.br) e do Portal de Periódicos da Capes (periodicos.capes.gov.br). Nessas três plataformas foram pesquisados trabalhos a partir das palavras-chave: sala de aula invertida.

De acordo com Galvão (2010):

Realizar um levantamento bibliográfico é se potencializar intelectualmente com o conhecimento coletivo para se ir além. É munir-se com condições cognitivas melhores, a fim de: evitar a duplicação e pesquisas, ou quando for de interesse, reaproveitar e replicar pesquisas em diferentes escalas e contextos; observar possíveis falhas nos estudos realizados; conhecer os recursos necessários para a construção de um estudo com características específicas, desenvolver estudos que cubram as lacunas na literatura trazendo real contribuição para a área de conhecimento [...] logo, a pesquisa inovadora, diferenciada do que foi até então produzido requer prévio levantamento bibliográfico de qualidade- (GALVÃO, 2010, p. 1).

$\mathrm{Na}$ primeira busca no portal de periódicos da Capes, foram pesquisados artigos, considerando o período compreendido entre 2010-2019, com os descritores "Sala de Aula Invertida" chegando ao número inicial de 66 artigos. Para filtrar os trabalhos encontrados, adotamos como critério de inclusão os trabalhos em português. Após a análise dos resumos, chegamos ao número de 13 artigos, conforme o quadro a seguir:

Quadro 1: Busca de artigos no portal de periódicos da Capes

\begin{tabular}{|c|c|c|}
\hline Valente (2013) & Formação de professores & $\begin{array}{c}\text { Aprendizagem Ativa no Ensino Superior: } \\
\text { a proposta da sala de aula invertida. }\end{array}$ \\
\hline Souza e Silva (2016) & Ciências Humanas & $\begin{array}{c}\text { Relato de uma experiência utilizando o } \\
\text { método da sala de aula invertida - } \\
\text { flipped classroom }\end{array}$ \\
\hline Pavanelo et al (2017) & Matemática & $\begin{array}{c}\text { Sala de Aula Invertida: a análise de uma } \\
\text { experiência na disciplina de Cálculo I }\end{array}$ \\
\hline
\end{tabular}




\section{sala \\ de $\theta$ em \\ aula foco}

\begin{tabular}{|c|c|c|}
\hline Camillo (2017) & Educação à distância & $\begin{array}{l}\text { Blended Learning: uma proposta para o } \\
\text { ensino híbrido }\end{array}$ \\
\hline Moura (2017) & Língua Portuguesa e Literatura & $\begin{array}{l}\text { Metodologias ativas de aprendizagem } \\
\text { que desafiam os alunos, mediadas por } \\
\text { tecnologias digitais. }\end{array}$ \\
\hline Leite (2017) & Química & $\begin{array}{l}\text { Sala de Aula Invertida: uma análise das } \\
\text { contribuições e de perspectivas para o } \\
\text { Ensino de Química }\end{array}$ \\
\hline Fini (2018) & Administração & $\begin{array}{l}\text { Metodologias inovadoras de } \\
\text { aprendizagem e suas relações com o } \\
\text { mundo do trabalho: desafios para a } \\
\text { transformação de uma cultura. }\end{array}$ \\
\hline Colombo et al (2014) & Informática & $\begin{array}{l}\text { A ferramenta wink e o modelo "sala de } \\
\text { aula invertida" aplicados ao ensino de } \\
\text { programação }\end{array}$ \\
\hline Oliveira (2018) & Matemática & $\begin{array}{l}\text { Sala de aula invertida nas aulas de } \\
\text { matemática na formação do pedagogo } \\
\text { em tempos de cibercultura }\end{array}$ \\
\hline $\begin{array}{l}\text { Bizolatti; Coelho Neto } \\
\qquad(2018)\end{array}$ & Matemática & $\begin{array}{l}\text { Sala de Aula Invertida: possíveis } \\
\text { aproximações para o ensino da } \\
\text { Matemática }\end{array}$ \\
\hline Frantz et al (2018) & $\begin{array}{l}\text { Tecnologia da Informação e } \\
\text { Comunicação }\end{array}$ & $\begin{array}{l}\text { Ensino híbrido com a utilização da } \\
\text { plataforma Moodle }\end{array}$ \\
\hline Valério et al (2019) & Ciências exatas & $\begin{array}{l}\text { A sala de aula invertida na universidade } \\
\text { pública Brasileira: evidências da prática } \\
\text { em uma licenciatura em ciências exatas }\end{array}$ \\
\hline $\begin{array}{l}\text { Ferrarini, Saheb e } \\
\text { Torres (2019) }\end{array}$ & Pedagogia & $\begin{array}{c}\text { Metodologias ativas e tecnologia digitais: } \\
\text { aproximações e distinções }\end{array}$ \\
\hline
\end{tabular}

Fonte: o autor (2019)

Conforme sinaliza a área de conhecimento ou disciplina, na busca por artigos encontramos apenas um artigo relacionado à disciplina de Língua Portuguesa, disciplina experimentada também por nós no uso da aula invertida. 


\section{sala \\ de $\oplus$ em \\ aula foco}

Dando continuidade, foram pesquisados também trabalhos no Banco de Teses e Dissertações da Capes considerando o mesmo período e o mesmo descritor, sendo identificados 18 trabalhos:

Quadro 2: Busca no banco de Teses e Dissertações no portal da Capes

\begin{tabular}{|c|c|c|}
\hline Cinto (2014) & Engenharia Elétrica & $\begin{array}{l}\text { Ambientes virtuais de aprendizagem: } \\
\text { propostas de editoração e visualização de } \\
\text { conteúdo educacional para aulas presenciais } \\
\text { e online }\end{array}$ \\
\hline Rodrigues (2015) & Ensino & $\begin{array}{l}\text { Sala de Aula Invertida: desafios apontados } \\
\text { por professores em uma instituição de } \\
\text { ensino médio }\end{array}$ \\
\hline Freitas (2015) & Física & $\begin{array}{l}\text { A percepção dos alunos da 1ạ série do } \\
\text { Ensino Médio na utilização do Método da } \\
\text { Flipped Classroom no ensino de Física }\end{array}$ \\
\hline Souza (2015) & Tecnologia & $\begin{array}{l}\text { Interação e silêncio em ambientes virtuais de } \\
\text { aprendizagem: um estudo de caso no } \\
\text { POSLING/CEFET-MG }\end{array}$ \\
\hline Tomanik (2015) & Física & $\begin{array}{l}\text { O uso do software Modellus na formação } \\
\text { inicial de licenciandos em física dentro da } \\
\text { abordagem metodológica da sala de aula } \\
\text { invertida }\end{array}$ \\
\hline Rolon (2016) & Administração & $\begin{array}{l}\text { Desenvolvimento e criação de uma nova } \\
\text { prática de trabalho em uma instituição de } \\
\text { ensino superior: um estudo da } \\
\text { aprendizagem e da mudança sob a } \\
\text { perspectiva da teoria social de Schatzki }\end{array}$ \\
\hline Hobmeir (2016) & Tecnologia & $\begin{array}{c}\text { Flipped Classroom: as práticas dos alunos } \\
\text { inseridos nos cursos semipresenciais de } \\
\text { gestão }\end{array}$ \\
\hline Machado (2016) & Ciência da Computação & $\begin{array}{l}\text { Uma abordagem colaborativa para } \\
\text { aprendizagem de programação de } \\
\text { computadores com a utilização de } \\
\text { dispositivos móveis }\end{array}$ \\
\hline
\end{tabular}




\section{sala \\ de $\theta$ em \\ aula foco}

\begin{tabular}{|c|c|c|}
\hline Milhorato (2016) & Administração & $\begin{array}{l}\text { Desafios e possibilidades da implantação da } \\
\text { metodologia sala de aula invertida: estudo } \\
\text { de caso em uma IES privada }\end{array}$ \\
\hline Ofugi (2016) & Inglês & $\begin{array}{c}\text { A sala de aula invertida como técnica } \\
\text { alternativa de ensino: um enfoque no } \\
\text { desenvolvimento da autonomia do aprendiz } \\
\text { de inglês como L2/LE }\end{array}$ \\
\hline Ribeiro (2016) & Formação de Professores & $\begin{array}{c}\text { Curiouser Lab: uma experiência de } \\
\text { letramento informacional e midiático na } \\
\text { educação }\end{array}$ \\
\hline $\begin{array}{l}\text { Yamamoto } \\
\text { (2016) }\end{array}$ & Administração & $\begin{array}{l}\text { Metodologias ativas de aprendizagem } \\
\text { interferem no desempenho de estudantes }\end{array}$ \\
\hline Santos (2016) & Tecnologia & $\begin{array}{l}\text { Uso de simuladores como ferramenta no } \\
\text { ensino e aprendizagem de redes de } \\
\text { computadores em um novo modelo de } \\
\text { ensino }\end{array}$ \\
\hline Schmitz (2016) & Tecnologia & $\begin{array}{l}\text { Sala de aula invertida: uma abordagem para } \\
\text { combinar metodologias ativas e engajar } \\
\text { alunos no processo de ensino-aprendizagem }\end{array}$ \\
\hline Knuth (2016) & Geografia & $\begin{array}{c}\text { Possibilidades no ensino de geografia: o uso } \\
\text { de tecnologias educacionais digitais }\end{array}$ \\
\hline Souza (2016) & Tecnologia & $\begin{array}{l}\text { Aula invertida: percepções de estudantes do } \\
\text { ensino superior tecnológico }\end{array}$ \\
\hline Vezu (2017) & Química & $\begin{array}{c}\text { Sala de aula invertida: uma proposta de } \\
\text { ensino para reações orgânicas de adição no } \\
\text { nível técnico }\end{array}$ \\
\hline Lucchetti (2017) & Medicina & $\begin{array}{l}\text { Avaliação de estratégias de ensino sobre } \\
\text { "geriatria e gerontologia” na graduação em } \\
\text { medicina. }\end{array}$ \\
\hline
\end{tabular}

Fonte: o autor (2019)

Diante das pesquisas encontradas, observamos o uso mínimo da sala de aula invertida na disciplina de Língua Portuguesa e Redação, o que reforça a necessidade desse estudo. 


\section{sala \\ de $\oplus$ - em \\ aula foco}

\section{A SALA DE AULA INVERTIDA COMO METODOLOGIA ATIVA DE APRENDIZAGEM}

Na sala de aula invertida, a ideia é não trabalhar a transmissão de conteúdo em sala, mas a aplicação dos assuntos vistos em casa, de maneira prática, dinâmica e ativa por parte do aluno. Como consequência de uma aprendizagem ativa, pode-se promover também uma aprendizagem colaborativa, no que tange a promoção de atividades em grupos. Para tanto, a disposição das carteiras pode ser alterada, promovendo, ainda que de forma tímida, o desenvolvimento de uma nova cultura da sala de aula, diferente da que estamos acostumados.

Essa nova formação facilita os trabalhos em grupo. Alunos enfileirados, olhando todos numa única direção, pressupõe que alguém estará detendo o conhecimento, situação que nos remete a figura docente como alguém que mais que é a fonte da sabedoria, e os ouvintes são os receptáculos. Próximo a isso, Freire (2013) denomina os que recebem a informação de tábula rasa ou folha em branco, de acordo com a abordagem tradicional.

A mensagem ativa da sala de aula invertida diz que o professor é o mediador, e que o aluno pode ser agente no seu processo de aprendizagem. De acordo com Oliveira, Araújo e Veit (2016), a sala de aula invertida apresenta algumas características consideradas positivas:

a) Ressignifica o papel do professor;

b) Não implica necessariamente no uso de videoaulas;

c) Coloca o aluno no centro do processo educativo;

d) Podem auxiliar no desenvolvimento de hábitos de estudos nos estudantes;

e) Pode estimular o desenvolvimento de habilidades relacionadas ao trabalho colaborativo;

f) Leva em consideração os conhecimentos prévios dos alunos;

g) Auxilia os alunos no desenvolvimento da capacidade de reflexão e da habilidade de elaborar boas perguntas;

h) Lida com a heterogenia na sala de aula.

Como em toda técnica, ela carrega suas dificuldades, assim, os autores apresentam também os desafios da proposta: 


\section{sala \\ de $\oplus$ em \\ aula foco}

a) Conteúdo programático das disciplinas extenso e tempo limitado para inverter a sala de aula podem ser agravantes;

b) A estrutura da escola é rígida e limita qualquer tentativa de inovação;

c) Os alunos não são acostumados a estudar fora da sala de aula;

d) As turmas são heterogêneas e o número de alunos por turma é elevado.

Considerando o exposto até o momento, pode-se erroneamente sugerir uma ideia de tranquilidade ao professor, que deixará de dar aula, antecipando o conteúdo ao discente e "esquivando-se", dessa maneira, de sua obrigação docente. Pode-se pensar também que adotar a Sala de Aula Invertida é massificar o aluno com vídeos ou com um curso on-line, muito menos deixar o aluno a mercê de um trabalho isolado. É interessante esclarecer que na promoção dessa metodologia, o professor terá que planejar suas aulas, talvez até mais de que fazia, em virtude de estar lidando com uma nova forma de praticar a ação docente. Faz parte da premissa da inversão da sala de aula a mediação docente, orientando o aluno dentro e fora da sala de aula, tirar dúvidas, criar estratégias instigantes para o tempo que consequentemente sobrará em sala de aula.

O que fazer com o tempo que sobra em sala de aula, quando o aluno já recebeu o conteúdo em sua casa? É interessante destacar que a priori, essa mudança pode ser lenta. Não se pode afirmar que os alunos farão a sua parte de imediato. É preciso levar a nova forma de aprender com paciência, e no primeiro momento, caso os alunos, ou apenas um grupo não tenha exercido o que prevê a programação de assistir o vídeo ou ler algum material em casa, que se criem oportunidades, ainda em sala, do cumprimento dessa tarefa.

Sugere-se, então, que o professor promova atividades em ilhas, o que podemos denominar estações de trabalho. Por conseguinte, essas estações variam, proporcionando a participação de todos em todas as atividades, e isso se chama rotação por estações, conforme orienta Bacich, Tanzi Neto e Trevisani (2015). Nessas estações, os alunos poderão trabalhar a partir de seus níveis de participação na proposta, por exemplo, os alunos que não viram o vídeo/material, passarão a 


\section{sala

ver, e os que já cumpriram essa etapa, passarão para outra atividade, sequência da atividade anterior, sempre mediados pelo professor.

Baseado, ainda, nos autores Bergmann e Sams (2012), considerando uma aula de 50 minutos, apresentamos um quadro que compara o tempo em ambas as situações:

Quadro 3: Tempo gasto na Aula Tradicional x Tempo gasto na Sala de Aula Invertida

\begin{tabular}{|c|c|c|c|}
\hline $\begin{array}{c}\text { Momento inicial } \\
\text { motivacional }\end{array}$ & 5 minutos & $\begin{array}{c}\text { Momento inicial } \\
\text { motivacional }\end{array}$ & 5 minutos \\
\hline $\begin{array}{c}\text { Correção das atividades } \\
\text { propostas para casa }\end{array}$ & 15 minutos & $\begin{array}{c}\text { Discussão sobre o } \\
\text { conteúdo visto em casa }\end{array}$ & 10 minutos \\
\hline $\begin{array}{c}\text { Exposição oral ou leitura } \\
\text { sobre o conteúdo }\end{array}$ & $20-30$ minutos & $\begin{array}{c}\text { Apresentação e } \\
\text { esclarecimento de } \\
\text { dúvidas }\end{array}$ & 10 minutos \\
\hline $\begin{array}{c}\text { Práticas em sala de aula } \\
\text { (individuais ou } \\
\text { coletivamente) }\end{array}$ & $\begin{array}{c}\text { (Se o tempo da aula não } \\
\text { for bem cronometrado, } \\
\text { há uma grande } \\
\text { probabilidade de não } \\
\text { sobrar esse tempo) }\end{array}$ & $\begin{array}{c}\text { Práticas em sala de aula } \\
\text { (individuais ou } \\
\text { coletivamente) }\end{array}$ & 25 minutos \\
\hline
\end{tabular}

Fonte: O autor, baseado em Bergmann e Sams (2012)

Na proposta da sala de aula invertida há um replanejamento da prática docente, na qual o professor deixa de assumir total responsabilidade no processo de ensino-aprendizagem, o que pode se configurar como uma barreira. A exposição oral do docente (que se configura também como um desgaste físico, principalmente para a maioria dos casos em que o professor sai de uma sala imediatamente para outra) é substituída pela promoção de um aprendizado significativo, no processo de avaliação, na personalização ${ }^{5}$ do ensino (foco às necessidades individuais dos

\footnotetext{
${ }^{5}$ Ao trazer a premissa da personalização do ensino, é interessante dizer que diante da diversidade de alunos, "o professor deve ter uma compreensão flexível e multifacetada, adequada à oferta de explicações diferentes dos mesmos conceitos e princípios". (SHULMAN, 2014, p. 208)
} 


\section{sala \\ de $\oplus$ em \\ aula foco}

-REVISTA ELETRONNICA

discentes), no esclarecimento de dúvidas, etc. Conteúdo antecipado, bem como, uma menor quantidade de apresentação passiva de conteúdo é o cerne da sala de aula invertida. "É importante que o aluno compreenda que também é responsável pela sua aprendizagem" (MATTAR, 2017, p. 113).

No que diz respeito às tendências pedagógicas que envolvem a proposta de sala de aula invertida, podemos trazer como suporte a progressista libertadora. Proposta por Paulo Freire, ele enfatiza que os espaços de produção de conhecimento perpassam as quatro paredes da sala de aula, podendo ser administrada em outros espaços da unidade de ensino, quiçá, além-muros. No mundo pós-moderno, cercado pelas TDIC, essa ideia é reforçada pelo crescente número de informações que circulam via internet, redes sociais, plataformas de produção de conhecimento, ou seja, assim como a escola não é a única fonte de conhecimento, o professor também deixa de ser uma das únicas fontes de consulta.

Relaciona-se com o humanismo, proposto por Carl Rogers (1973), autor desse enfoque teórico de aprendizagem, expressando as ideias básicas do: aprender a aprender, liberdade para aprender, ensino centrado no aluno e crescimento pessoal. O autor defende que o aluno precisa tomar consciência de suas necessidades, autodirigir a sua aprendizagem (significativa), desenvolver autonomia, carecendo de liberdade para vivenciar esse processo (MOREIRA, 2011). Partindo para as relações de poder em sala, o docente passa a ser mediador, não ensina de forma autoritária, mas promove a facilitação da aprendizagem, criando um clima sem censuras.

\section{A INTERNET COMO APOIO À SALA DE AULA INVERTIDA}

Com o auxílio da rede mundial de computadores (Internacional-Networking ou apenas internet) o aluno pode ampliar as possibilidades ativas de aprendizagem, em qualquer lugar, a qualquer hora. Segundo Moran (2015, p. 16), "os métodos tradicionais, que privilegiam a transmissão de informações pelos professores, faziam sentido quando o acesso à informação era difícil". Hoje, o professor não é mais considerado a única fonte de conhecimento, nem a sala de aula tradicional o único espaço de aprendizagem, passando a existir modelos inovadores de 


\section{sala \\ de $\oplus$ em \\ aula foco}

ensino, emergindo de uma prática, que apesar de se espelhar no Escolanovismo ${ }^{6}$ pela luta contra o tradicionalismo nas escolas, se propõe nova, em vista do suporte tecnológico que dispomos atualmente.

A transmissão e assimilação de conhecimento, não tem o mesmo significado de outrora. De acordo com Moran "os métodos tradicionais, que privilegiam a transmissão de informações pelos professores, faziam sentido quando o acesso à informação era difícil” (MORAN, 2015, p._16). A educação, se vinculada às novas metodologias e às novas tecnologias se configura como um ensino híbrido, ou blended learning ${ }^{7}$, uma tendência da Educação do nosso século, que mescla o ensino presencial e o ensino virtual, vinculando educação e tecnologia. Christensen, Horn e Staker (2013) afirmam que no ensino híbrido o aluno aprende de forma on-line, controlando seu ritmo de estudo, de casa ou de outro lugar de sua preferência, e em parte, em um lugar físico supervisionado pelo professor, como por exemplo, a escola.

Apesar dos desafios, entendemos que trabalhar com metodologias ativas, especificamente com a sala de aula invertida, diz muito da realidade do aluno contemporâneo. A relação da SAI com as TDIC possibilita aos usuários ter acesso aos mais variados conteúdos, disponibilizados ou não pelos professores, gerando novas oportunidades de aprendizado. A Sala de Aula Invertida é considerada a porta de entrada para outras metodologias ativas de aprendizagem, pela maneira flexível de inserir-se no contexto da sala de aula tradicional, de forma híbrida, ou seja, reunindo elementos de forma on-line e presencial, conjuntamente.

Segundo Valente "metodologias ativas constituem alternativas pedagógicas que colocam o foco do processo de ensino e de aprendizagem no aprendiz, envolvendo-o na aprendizagem por descoberta, investigação ou resolução de problemas" (VALENTE, 2018, p. 27). Assim, podemos dizer que a Sala de Aula Invertida é uma metodologia ativa de aprendizagem centrada no aluno, deixando de protagonizar somente o professor.

\footnotetext{
${ }^{6}$ O termo advém da Escola Nova, chamada também de Escola Ativa, movimento que buscou a superação do ensino tradicional. Iniciada na Europa pelo suíço Ferrière chega ao Brasil em 1920.

${ }^{7} \mathrm{O}$ verbo blend em língua inglesa significa misturar. Combinar estudo presencial com estudo a distância.
} 


\section{sala \\ de $\oplus$ em \\ aula foco}

-REVISTA ELETRÔNICA

Conforme sinaliza Horn e Staker (2015), reforçado por Jaime, Koller e Graeml (2015), nesse modelo, os alunos participam de momentos on-line, apresentados virtualmente aos conteúdos expositivos, assumindo a responsabilidade pelo estudo teórico, sendo que a aula presencial servirá para aplicar, na prática, aquilo que previamente foi estudado de maneira autônoma. Nesse sentido, de acordo com Mattar (2017) o aluno precisa compreender a importância de se responsabilizar por sua aprendizagem.

A sala de aula invertida é um facilitador para a promoção da autonomia do estudante, e seu uso contribui de maneira significativa no processo de ensino-aprendizagem. Usando aplicativos, como o Telegram, outro exemplo, pode-se trazer algo novo para o aluno, otimizando também o tempo do docente em sala de aula, visto que, se o aluno tem acesso ao conteúdo antes da aula, o mesmo poderá diminuir o tempo dedicado à oralidade em sala, havendo possibilidade de mais interação entre o professor e o aluno, bem como, mais dedicação à resolução de problemas e dúvidas.

\section{ESTUDO DE CASO: O APLICATIVO TELEGRAM COMO FERRAMENTA DE ENSINO-APRENDIZAGEM NAS AULAS DE LÍNGUA PORTUGUESA}

Aqui, faremos um relato de prática do uso de sala de aula invertida nas aulas de Língua Portuguesa em turmas de terceira série do Ensino Médio de uma escola pública da rede estadual de Sergipe: o Centro de Excelência Atheneu Sergipense. A motivação para essa ação surgiu das leituras sobre a temática, unindo-se à ideia de proporcionar um ensino mais dinâmico e com um potencial de retorno muito maior que o convencional, o que nos levou a adotar uma ferramenta digital e móvel para interagir com os alunos.

Não há como negar que os smartphones fazem parte da vida dos estudantes, entretanto não podemos enxergá-lo como um "inimigo" responsável por provocar a perda de atenção dos alunos, mas como um parceiro que nos permite infinitas possibilidades de trabalho, como também dinamizar as aulas e conquistar cada vez mais estudantes para apreensão dos conteúdos trabalhados. Com o uso do smartphone, podemos oferecer materiais antecipadamente, fazer pesquisas, como também tirar dúvidas dos alunos naqueles momentos em que não estamos 


\section{sala \\ de $\oplus$ em \\ aula foco}

próximo a eles, ou até mesmo, através de salas de bate-papo compartilhar dúvidas que podem ser sanadas por outros colegas, tornando assim o ensino-aprendizagem uma experiência de compartilhamento e trabalho em equipe.

Face a isso, em 2018, ainda de maneira experimental, passamos a utilizar em sala de aula um aplicativo de mensagens, o Telegram, concorrente direto do famoso Whatsapp. A escolha pelo primeiro deveu-se a alguns motivos pré-estabelecidos, de modo a manter a eficácia daquilo que seria proposto a eles e que detalharemos abaixo.

\section{A) $\mathbf{O}$ contexto}

O trabalho foi desenvolvido em uma escola pública da rede estadual de Sergipe, o Centro de Excelência Atheneu Sergipense, em cinco turmas de Língua Portuguesa da terceira série do Ensino Médio. Na escola, a carga horária da disciplina é de seis aulas por semana, de modo que nós dividimos em três conteúdos: Gramática, Literatura e Redação. O uso do Telegram foi especificamente usado para as aulas de Redação.

O primeiro passo foi solicitar aos alunos que baixassem o aplicativo, que é gratuito, na loja do seu sistema operacional (Android ou iOS). Inicialmente, houve resistência por parte deles, afinal, eles estavam acostumados com o Whatsapp e migrar para um aplicativo com interface diferenciada causou um certo receio, entretanto, à medida que os primeiros foram fazendo o download e utilizando-o perceberam que as funções eram similares.

\section{B) “Professor, já aprendi a mexer! E qual a diferença para o WhatsApp?"}

Uma das principais perguntas que os alunos faziam após o período de adaptação ao Telegram eram os motivos pelos quais não fiz um simples grupo de Whatsapp, que para eles surtiria o mesmo efeito. E nesse momento vinha a parte mais legal de todo o projeto: romper com o pré-estabelecido e mostrar para eles o mundo de possibilidades que a tecnologia pode nos oferecer. Abaixo, elenco os motivos do Telegram ser melhor que o Whatsapp para esse projeto: 


\section{sala \\ de $\oplus$ em \\ aula 1 foco}

1. Controle do que é postado: hoje, o Whatsapp já possui o recurso de somente o administrador do grupo fazer as postagens, mas quando lançamos o projeto esse recurso ainda não estava disponível. Sendo assim, manter as postagens centradas em uma única pessoa contribuiria para manter o foco do grupo;

2. Um aplicativo dedicado: dissemos a eles que o Whatsapp era comumente utilizado para falar com várias pessoas, grupos de amigos e família, de modo que as notificações poderiam se confundir com as minhas. O uso de um aplicativo exclusivo para a turma, facilitaria na hora que as mensagens fossem enviadas, pois já saberiam que era algo sobre a disciplina.

3. Quem chega depois também tem acesso ao conteúdo: nos grupos de Whatsapp, quando você é adicionado depois de algum tempo de início das conversas, não é possível ter acesso aos materiais e conversas postados. No Telegram é diferente, quem entra depois terá seu aplicativo sincronizado e receberá tudo o que foi postado. Isso ajuda àqueles alunos que entram na escola em momentos diversos, àqueles que demoraram a fazer o download etc.

4. Grupos ou Canais: no Telegram há o recurso canais. Uma forma de adicionar várias pessoas em um grupo, mas no caso dos canais, só o administrador faz a postagem e interage. Foram criados três canais:

a) Sala de Redação Dicas: onde são postadas dicas sobre qualquer assunto que diga respeito a produção textual ou atualidades que possam ajudar no desenvolvimento da redação;

b) Sala de Redação News: onde todas as manhãs são feitas postagens das capas dos principais jornais do país para que eles possam se manter atualizados;

c) Sala de Redação Propostas: onde são postadas, semanalmente, as propostas de redação que trabalharemos ao longo da semana. 


\section{sala \\ de $\oplus$ - em \\ aula foco}

\section{C) Resultados}

Já estamos no terceiro ano de aplicação do projeto, e agora os canais possuem alunos e exalunos que ainda se beneficiam do material ali postado. Mesmo estudantes que ainda não são das terceiras séries pedem para serem adicionados, o que mostra o potencial de encanto que uma aula híbrida é capaz. Os alunos elogiaram o fato de já irem à aula sabendo o que seria discutido, o que nos fazia ganhar tempo para as discussões, como também para amadurecê-las e o rendimento dos estudantes sempre foi e continua sendo elevados.

Por fim, o melhor retorno que tivemos foi da avaliação externa, no caso do Ensino Médio, o ENEM. Desde 2017 que as notas de redação das turmas, as quais o Telegram e as Salas de Redação estiveram presentes, cresceram exponencialmente, comprovando mais uma vez a eficácia do método. O objetivo agora é capacitar outros professores para que possam valorizar e utilizar esses recursos como metodologia ativa de aprendizagem e quebrar paradigmas dos docentes que ainda veem a tecnologia como um obstáculo no âmbito escolar.

Destacamos algumas imagens no sentido de mostrar o ambiente do Telegram nas atividades pedagógicas propostas:

Figura 01 - Print das telas de conversas no Telegram

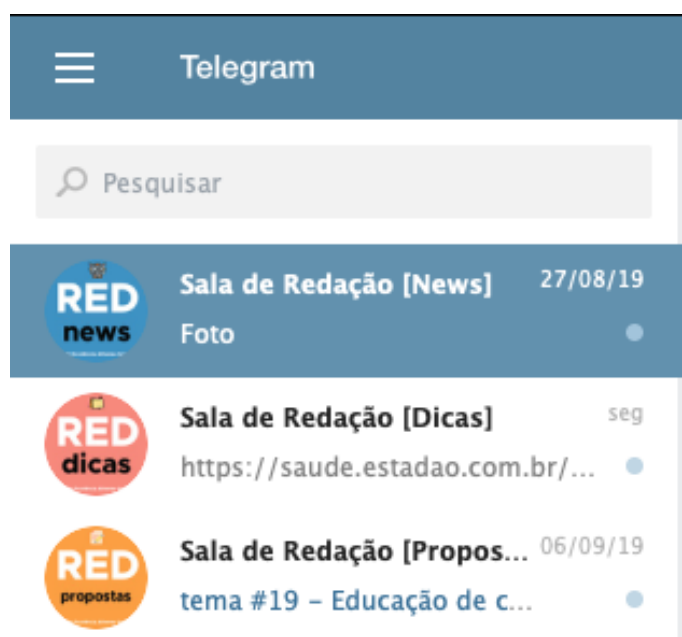

Fonte: Telegram (2019) 


\section{sala \\ de $\oplus$ em \\ aula foco}

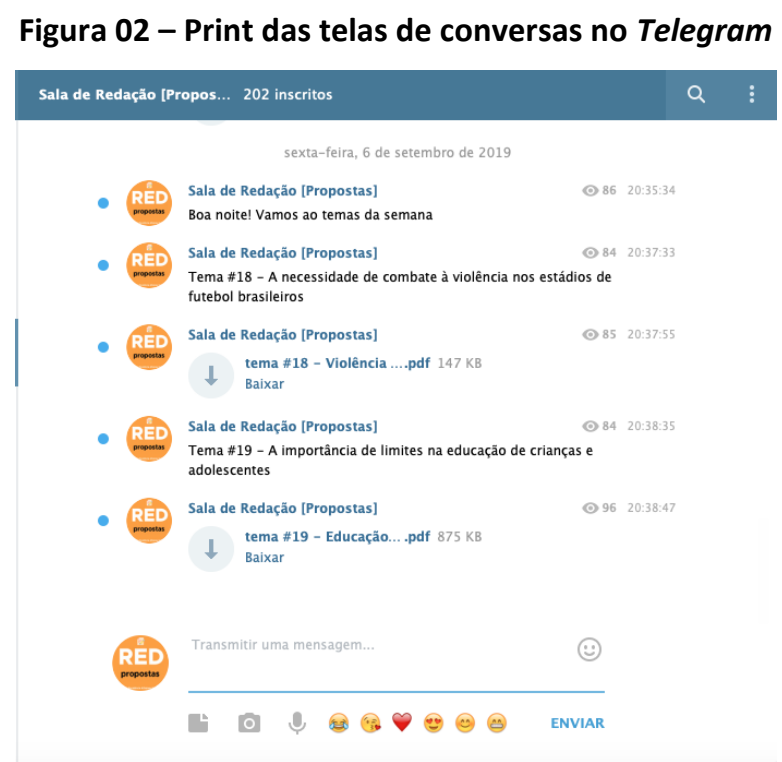

Fonte: Telegram (2019)

\section{CONSIDERAÇÕES FINAIS}

Foi possível verificar neste trabalho como as metodologias ativas de aprendizagem, especificamente a sala de aula invertida, ligada às TDIC influenciam a escola. Essa realidade nos atualizou quanto aos métodos e técnicas mais apropriados para o aluno hodierno. $O$ estudo revelou também de que maneira o aluno pode ser um agente ativo no meio escolar, e-sem tirar a importância do professor numa sala de aula e trazer o protagonismo do aluno à tona.

É inegável que ainda é um desafio integrar tecnologia e educação, de forma a atender aos interesses do homem moderno, enquanto lida com as mudanças geradas pelas novas tecnologias da informação e comunicação. A partir disso, surgem as dificuldades dos professores em acompanhar o aluno na utilização de instrumentos e ferramentas tecnológicas com a intenção de subsidiar o processo de ensino/aprendizagem. Assim, evidencia-se que a educação tradicional tem 


\section{sala

perdido um pouco de sentido e que a sala de aula como estamos acostumados, não é mais o único lugar onde se produz conhecimento.

\section{REFERÊNCIAS}

BACICH, L; TANZI NETO, A.; TREVISANI, F. M. (Org.). Ensino híbrido: personalização e tecnologia na educação. Porto Alegre: Penso, 2015.

BERGMANN J; SAMS, A. Flip Your Classroom: Reach Every Student in Every Class Every Day, USA, International Society for Technology in Education. 2012.

CHRISTENSEN, C. M.; HORN, M. B.; STAKER, H. Ensino híbrido: uma inovação disruptiva? Uma introdução à teoria dos híbridos. [S. I: s. n], 2013. Disponível em:

https://www.christenseninstitute.org/publications/ensino-hibrido/. Acesso em: 19 nov. 2018.

FREIRE, Paulo. Pedagogia do oprimido. 1. ed. Rio de Janeiro: Paz e Terra, 2013.

GALVÃO, Maria Cristiane Barbosa. O levantamento bibliográfico e a pesquisa científica. Ribeirão Preto: Universidade de São Paulo, 2010.

HORN, M. B.; STAKER, H. Blended: usando a inovação disruptiva para aprimorar a educação. Porto Alegre: Penso, 2015.

http://www.eca.usp.br/prof/moran/site/textos/educacao_online/contrib.pdf. Acesso em 11 mar 2019.

JAIME, M. P.; KOLLER, M. R. T.; GRAEML, F. R. La aplicación de flipped classroom en el curso de dirección estratégica. In: JORNADAS INTERNACIONALES DE INNOVACIÓN UNIVERSITARIA

EDUCAR PARA TRANSFORMAR, 12., 2015. Actas... Madrid: UNIVERSIDAD EUROPEA, 2015. p. 119133.

MATTAR, J. Metodologias Ativas: para a educação presencial, blended e a distância. São Paulo: Artesanato Educacional, 2017.

MORAN, J. M; MASETTO, M. T; BEHRENS, M. A. Novas Tecnologias e mediação pedagógica. 21. ed. São Paulo: Papirus, 2013.

MORAN, J. M. Mudando a educação com metodologias ativas. Coleção Mídias Contemporâneas. Convergência Midiáticas, Educação e Cidadania: aproximações jovens. Vol. II. P. 15-33. 2015. Disponível em http://www2.eca.usp.br/moran/wpcontent/uploads/2013/12/mudando_moran.pdf. Acesso em 19/11/2018.

MORAN, J. M. O vídeo na sala de aula. Revista Comunicação \& Educação. São Paulo, ECA-Ed. Moderna, [2]: 27 a 35, jan./abr. de 1995

MORAN, J. M. Desafios na comunicação pessoal. 3o ed. São Paulo: Paulinas, 2007. 


\section{sala \\ de $\oplus$ em \\ aula foco}

MOREIRA, M. A. Teorias de aprendizagem. 2. Ed. São Paulo: EPU, 2011.

OLIVEIRA, T. E., ARAUJO, I. S., VEIT, E. A. Sala de Aula Invertida (Flipped Classroom): inovando as aulas de física. Física na Escola, v. 14, n. 2, 2016. Disponível em:

http://www1.fisica.org.br/fne/phocadownload/Vol14-Num2/a02.pdf. Acesso em 22 jun. 2019.

ROGERS, C. Liberdade para Aprender. Belo Horizonte: Ed. Interlivros, 1973.

VALENTE, José Armando. Blended Learning e as mudanças no Ensino Superior: a proposta da sala de aula invertida. Educar em Revista: Dossiê Educação a Distância, Curitiba: UFPR, 2014, Edição especial n. 4/2014. p. 79-97 Disponível em: http://ojs.c3sl.ufpr.br/ojs2/index.php/educar. Acesso em: 12 nov. 2018. 